\title{
Dental Contribution to an Anthropological Forensic Case Work of Skeletal Remains in Miglionico Countryside (South Italy)
}

\author{
E. Nuzzolese*, ${ }^{*}$, C. Liuzzi $^{1}$, G. Quarta ${ }^{2}$, L. Calcagnile ${ }^{2}$ and G. Di Vella ${ }^{1}$ \\ ${ }^{1}$ Sezione di Medicina Legale, DiMIMP, Università degli Studi di Bari, Policlinico, piazza G. Cesare, 70125, Bari, Italy \\ ${ }^{2}$ CEDAD, Dipartimento di Ingegneria della Innovazione, Università del Salento, Cittadella della Ricerca (S.S. 7 per \\ Mesagne, Km. $7+300$ ), 72100 Brindisi
}

\begin{abstract}
This report contains the results of a forensic study of human remains discovered by a forester in the countryside surrounding Miglionico (Southern Italy) in August 2007. A total of 286 bone fragments were excavated at the scene and an osteological analysis was carried out by two forensic pathologists, one of which had a anthropological background. A forensic odontologist was also involved to ascertain the completeness of the skeletons and to make an inventory of the skeletal material. It was hoped also to establish a cause of death and period in which it occurred, and if possible to attempt to identify the individual. Age and odontological assessment was also provided.

This report will highlight the contribution of an odontological and radiological analysis in relation to fragments of maxillary bones with teeth in situ, and also with teeth lost post-mortem. Findings from morphological, dental and radiological examination, UV illumination in the compact bones and radioisotope scan $\left({ }^{14} \mathrm{C}\right)$ revealed these skeletal remains belonged to at least three separate individuals, dating between 600 and $1000 \mathrm{AD}$, and therefore having archaeological significance.

The case shows the relevance of forensic odontology in an anthropological evaluation which deals with discovered human remains of jaws and teeth.
\end{abstract}

Keywords: Forensic science, human remains, forensic radiology, forensic odontology, forensic anthropology.

\section{INTRODUCTION}

This report contains the results of a forensic study of human remains discovered by a forester in the countryside surrounding Miglionico (Southern Italy) in August 2007. The area is a protected wild life nature reserve covering an area of 2500 hectares which was established in 1976. Within the reserve there is a resevoir, the result of the construction of a dam. The remains were discovered in the clayey area around the lake having being uncovered by a mudslide. Some of the remains (vertebrae and fragments of pelvis) appeared to be embedded at the top of the ridge, others (femur, tibia, fibula and vertebras fragments) were found at the bottom of it, about 2 meters below ground level. After an initial inspection the recovery of the fragments commenced - those fragments stuck at the top of the ridge being removed first with the assistance of firemen. It was in fact, necessary to remove huge amounts of the soil in order to reach the bone fragments, with the ever present risk of landslide. 286 bone fragments were excavated and recovered from the scene (Fig. 1). The forensic team was asked by the Judge to provide an expert opinion on the nature of the remains, and, should they prove human, a cause and period of death together with any other relevant data such as an identification in one were possible.

An osteological analysis was carried out by two forensic pathologists, who had a background in anthropology, and a

*Address correspondence to this author at the Sezione di Medicina Legale, DiMIMP, Università di Bari, Policlinico, piazza G. Cesare, 70125, Bari, Italy; Tel +390805042555; Fax +3908022031198; E-mail: emilionu@tin.it forensic odontologist, to ascertain the completeness of the skeletons and compile an inventory of the skeletal material. Odontological and radiological analysis of fragments of maxillary bones and teeth was also performed.

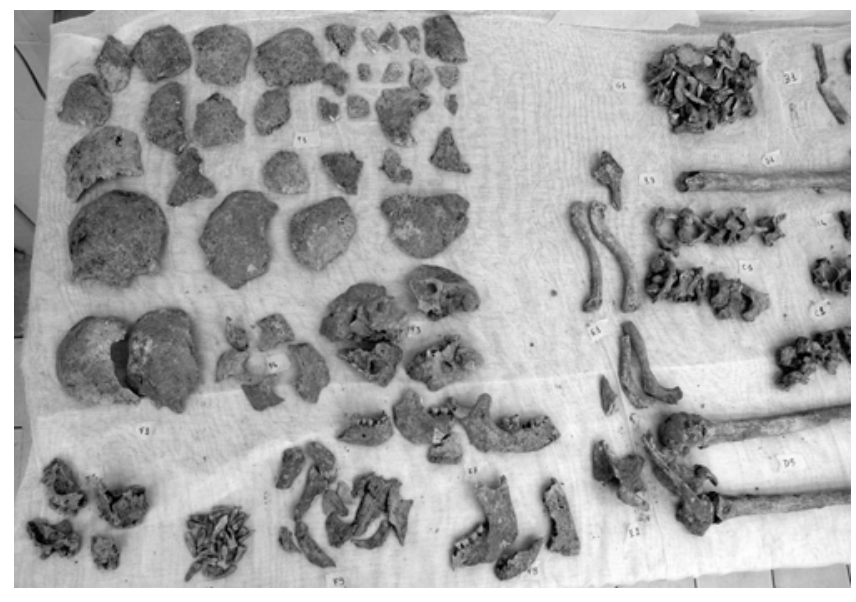

Fig. (1). Part of the bone fragments recovered from the excavation site: 286 bone fragments were excavated and recovered from the scene.

\section{METHODS AND PROCESS}

The skeletal material was analysed according to the standards laid out by the guidelines recommended by the British Association of Biological Anthropologists and Osteologists in conjunction with English Heritage [1]. 


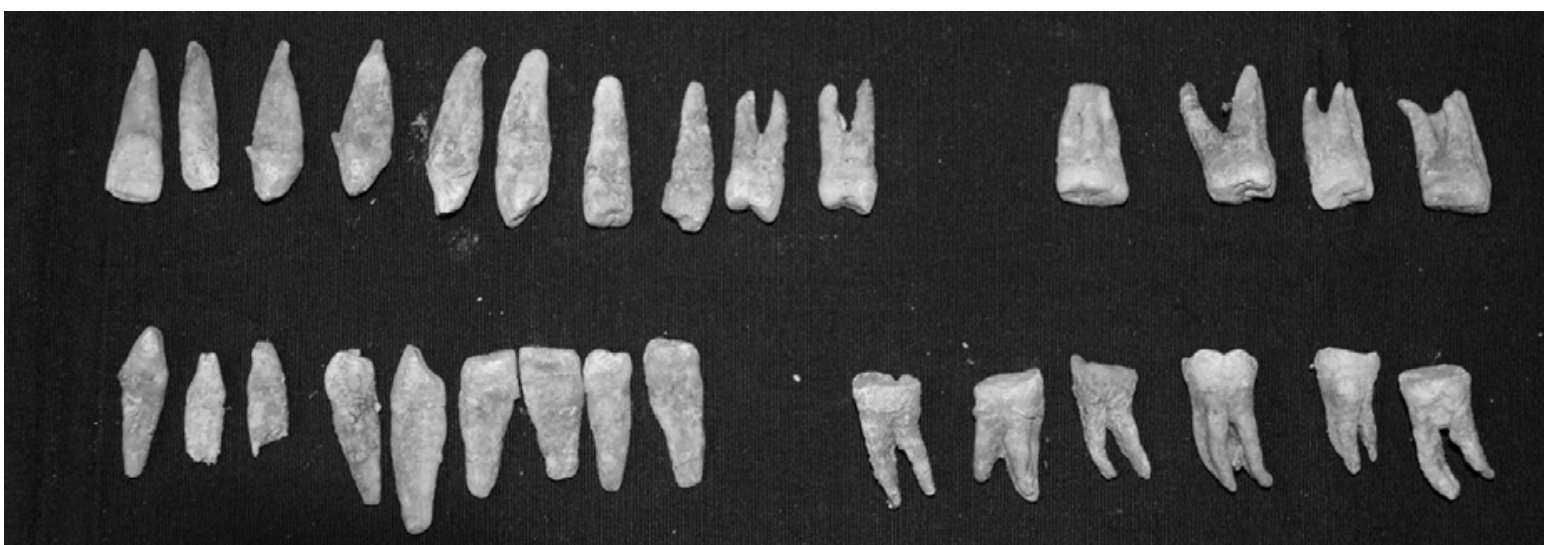

Fig. (2). Teeth recovered from the excavation site: 47 permanent teeth (29 teeth lost post mortem).

Recording of the material was carried out using the recognised descriptions contained in Standards for Data Collection from Human Skeletal Remains by Buikstra and Ubelaker [2] and digital photographs have been used for illustration. The material was analysed macroscopically and, where necessary, with the aid of a magnifying glass for identification purposes. The skeletal material was catalogued in:

A. Pelvis and lower limbs: 5 long bone fragments; 2 left tibial fragments; 1 left femur; 1 right tibial fragment; 1 right femoral fragment; 2 left hip fragments with acetabulum cavity; 5 pelvic fragments; 1 right tibial fragment; 1 right femoral fragment; 1 right hip fragment;

B. Ribs: 46 rib fragments;

C. Vertebra: 13 cervical vertebral fragments; 16 thoracic vertebrae; 5 lumbar vertebral fragments; 3 fragments of sacral vertebrae ;

D. Upper Limbs: 1 left humeral fragment; 4 left radial fragments; 2 left ulna fragments; 5 unidentified upper limb long bones; 4 humeral fragments with two humeral heads; 3 right ulna fragments; 31 metacarpal bone fragments, proximal, middle and distal phalanges right and left;

E. Clavicle and Scapula: 5 clavicle fragments; 2 right scapula fragments; 1 left scapula joint cavity;

F. Skull bones: 33 skullcap fragments; 2 occipital fragments with nape crests; 4 temporal fragments with mastoid; 5 orbital and zygomatic fragments; 4 maxillary fragments with 18 permanent teeth; 29 permanent teeth with highly worn occlusal face; 4 right hemimandible fragments; 3 left mandible fragments; 12 mandible fragments;

G. Commingled and crushed bones: 31 small fragments of various skeletal segments.

No significant pathological changes were observed in the skeletal remains of the individuals.

Both morphological and instrumental methods were used to determine the age at inhumation [3-7]. From a forensic point of view correct interpretation of the events surrounding death depends on the taphonomic process, distinguishing possible scavenger modifications from perimortem trauma.
Two bone samples were sent to a Lab (CEDAD Center) in order to perform $\mathrm{C}^{14}$ radiocarbon dating. Samples were analysed and the results calibrated to a calendar date.

The odontologist made a reconstruction of jaw fragments and teeth using dental wax. Found teeth were repositioned in the correct alveoli, and it was possible to reposition all teeth, based on the occlusal match. The skeletal material analysed was catalogued as follows: 47 permanent teeth ( 29 of which lost post mortem) (Fig. 2); 64 skull fragments; 19 jaw fragments.

The macroscopic analysis revealed complete arches, with no evidence of dental treatment. There was a high degree of abrasion of the occlusal surfaces and no enamel hypoplastic defects. Only two dental pathologies were discovered - an abscess on a second left molar and some periodontal disease.

The reconstructed jaws underwent digital photography (Fig. 3), radiological imaging using a panoramic X-ray device (Proline XC, Planmeca) at $68 \mathrm{Kv} 8 \mathrm{~mA}$ exposure (Fig. 4). As dry bones had to be exposed to radiographic imaging a plastic glass filled with water was used in order to reduce significant burnout in the anterior region [8].

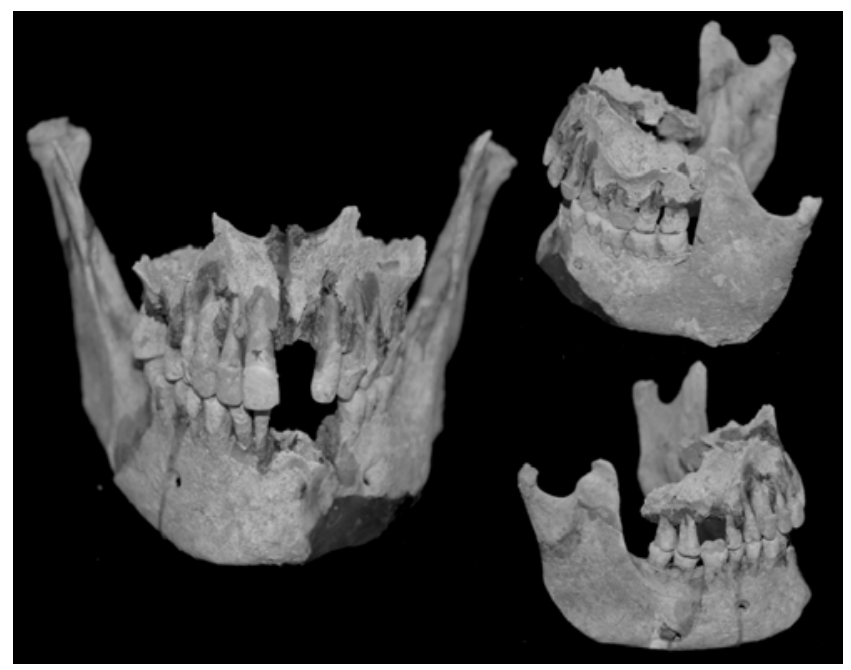

Fig. (3). Jaws fragments and teeth repositioned.

Digital periapical x-ray images of canines were also taken with a Nomad Examiner handheld portable device (Aribex inc.) and a Trophy Radiovideography digital sensor 
1

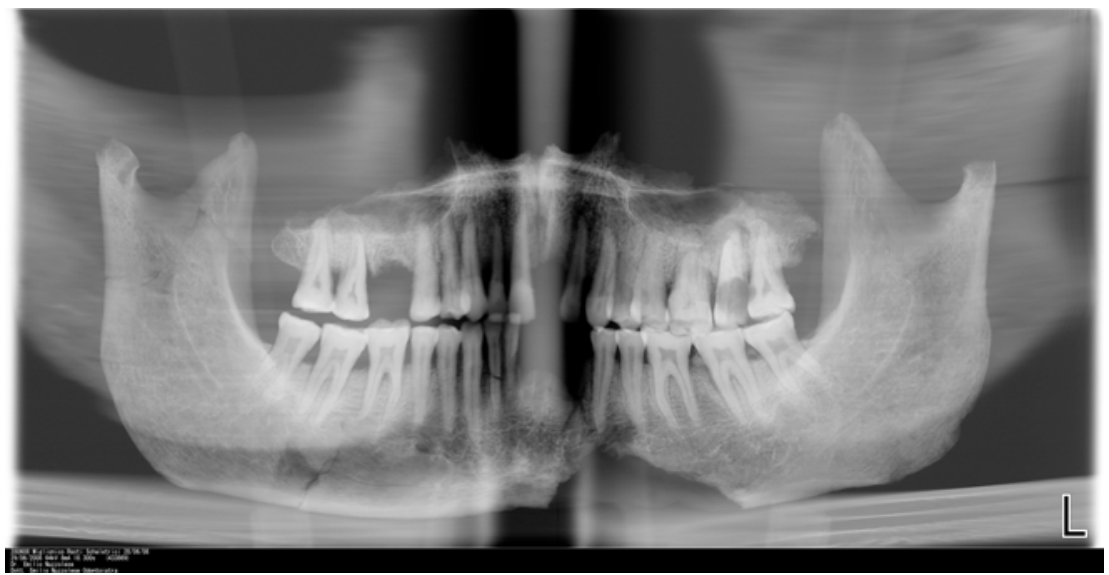

2

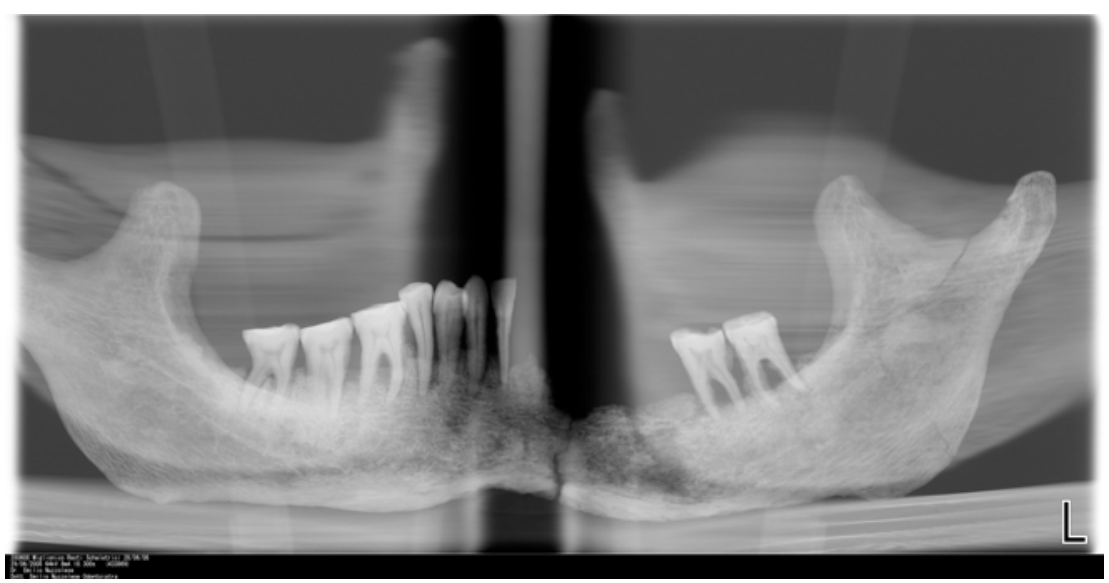

3

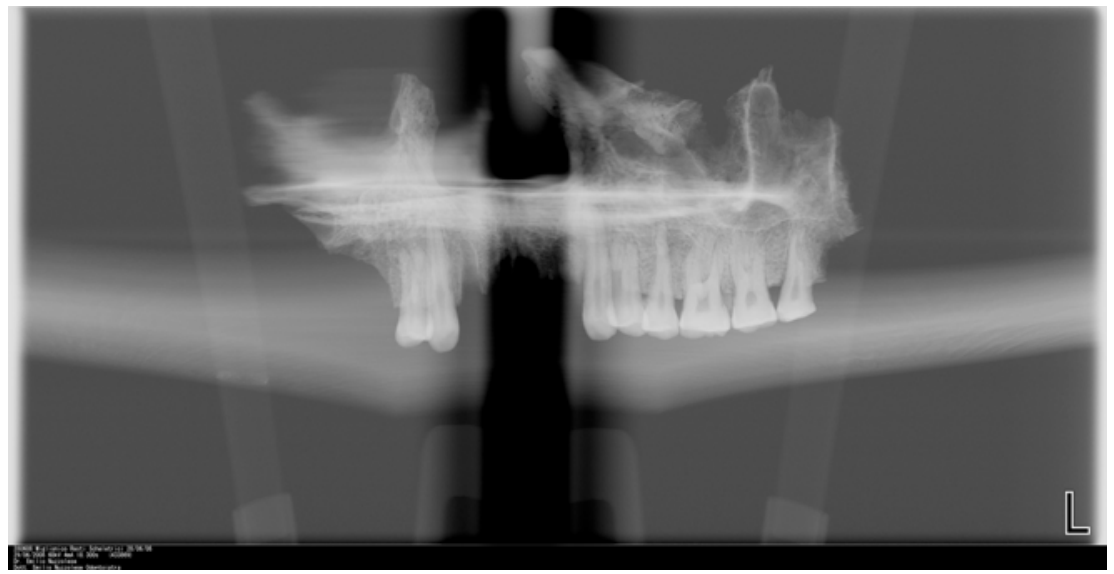

Fig. (4). 1. Adult 1: Panoramic X-ray image of the jaws. 2. Adult 2: Panoramic X-ray image of the mandible. 3. Adult 3: Panoramic X-ray image.

connected to a computer, using 0,02 seconds exposure time and $60 \mathrm{Kv}$ (Fig. 5). Periapical X-ray images of canines were employed to perform age assessment using Cameriere's method and Adobe Photoshop [9-11]. For macroscopic age assessment the most common item studied include teeth, cranial sutures, pubis, auricular surface of the ilium and sternal ribs. Dental wear is also widely used in anthropology, but may not be completely reliable. The method proposed by Cameriere et al. in 2006, which has been validated by further findings, considers the apposition of secondary dentine and has proved to be reliable regardless of the (age) historical period of the specimen and is particularly suitable for adult individuals.

\section{RESULTS}

The surface of the bone was on the whole intact but fragile, although some surface damage had occurred through root action and the post-depositional processes of the clay. Most 


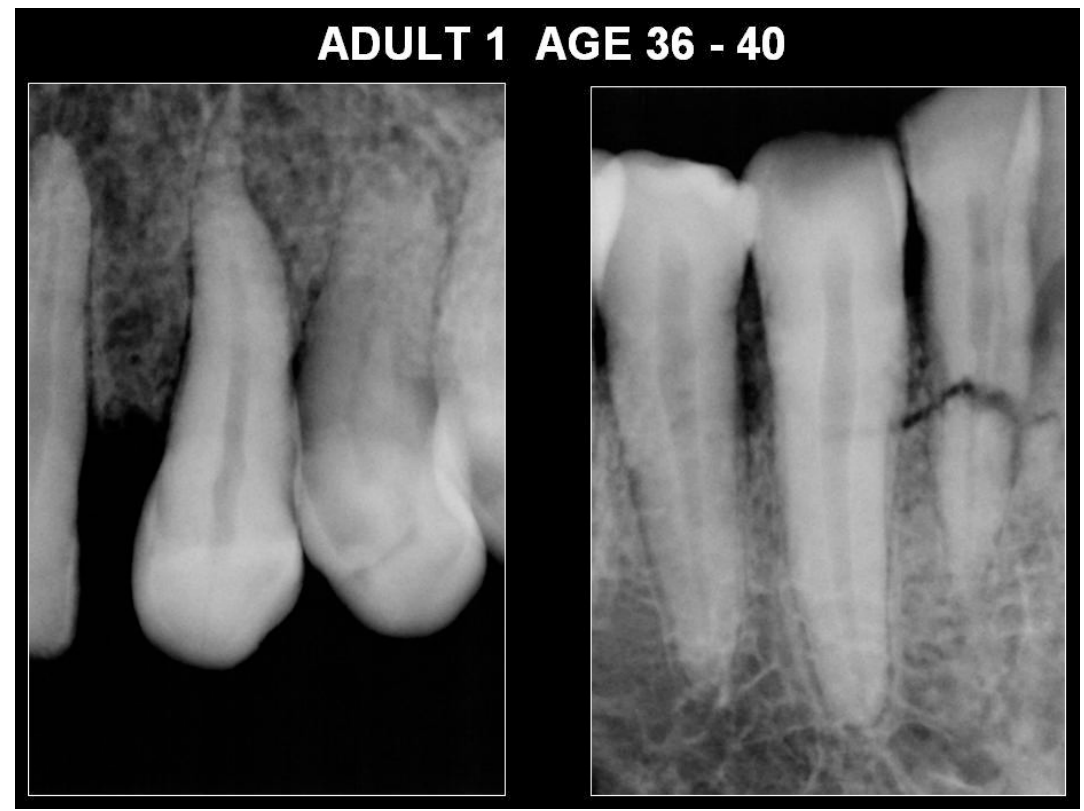

2

3
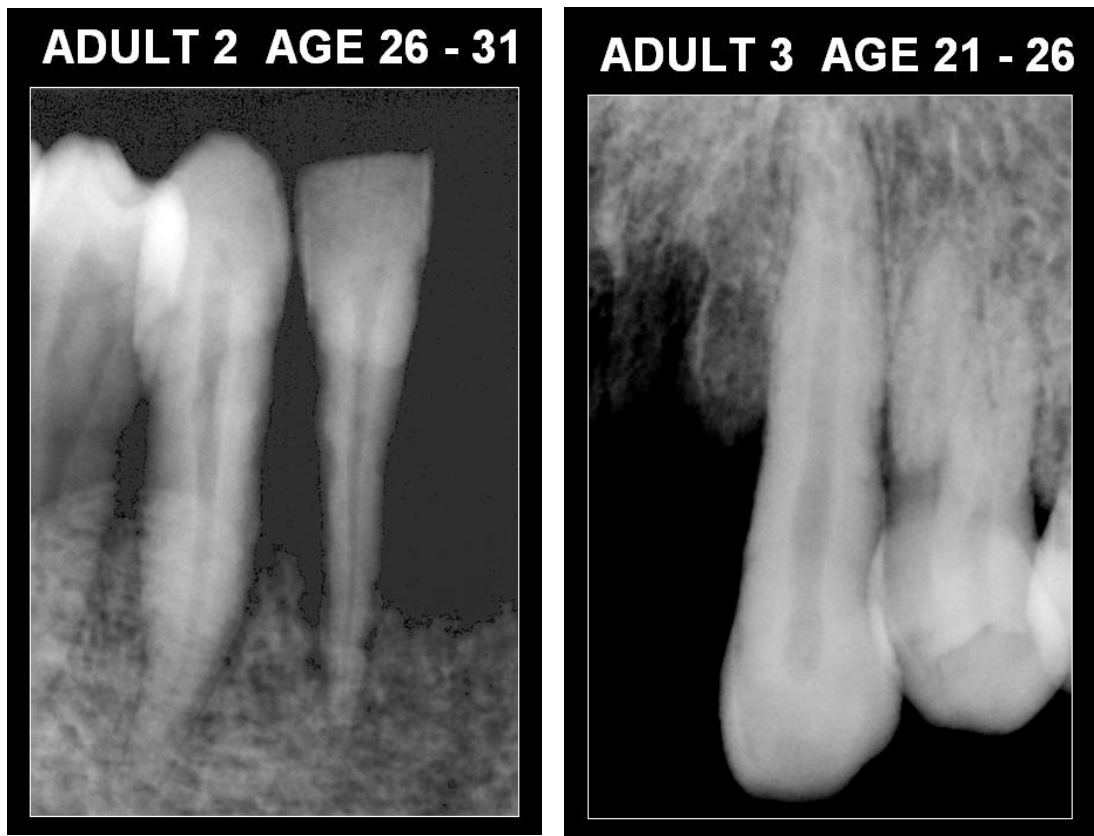

Fig. (5). 1. Periapical X-ray image of canines of adult 1 for the application of Cameriere's age estimation formula. 2. Periapical X-ray image of adult 2 canine for the application of Camierire's age estimation formula. 3. Adult 3: Periapical X-ray image of adult 3 canine for the application of Cameriere's age estimation formula.

of the material was fragmented. All breaks to the bone were old and weathered, with no sign of violent lesions. No complete long bones were found, therefore no estimation of stature could be made. However, the epiphyses of surviving long bones had fused diaphyses with no evidence of fusion lines. Fragments of same bone type indicated 3 separate adult individuals. Jaws and dental samples after the reconstruction and occlusal match also confirmed they had belonged to 3 separate adult individuals.

Findings from morphological and radiological examination, UV illumination in the compact bones and radioisotope scan $\left({ }^{14} \mathrm{C}\right)$ revealed these skeletal remains belonged to at least three separate individuals dating between 600 and 1000
$\mathrm{AD}$, thus having an archaeological relevance (Table 1, 2). The individuals appear to have been healthy, with no signs of any sustained periods of childhood stress from malnutrition or disease. The tooth surface wear and absence of dental treatment suggest the individuals do not belong to the modern era. Adobe Photoshop was used to determine canine pulp/tooth ratio in order to apply Cameriere's regression formula and finally assess the chronological age. The following age ranges were obtained: adult 1 age 36-40; adult 2 age 26-31; adult 3 age 21-26.

The location of the bones cannot be considered a burial, but most probably the result displacement during the excava- 
Table 1.

\begin{tabular}{|c|c|c|c|c|c|c|}
\hline $\begin{array}{l}\text { Inhumation } \\
\text { Age }\end{array}$ & solidity & $\begin{array}{l}\text { UV } \\
\text { fluores } \\
\text { cence } \\
\end{array}$ & Adipocere & $\begin{array}{l}\text { Marrow } \\
\text { cavity }\end{array}$ & $\begin{array}{l}\text { Soft } \\
\text { tissue }\end{array}$ & $\begin{array}{l}\text { Adipose } \\
\text { tissue }\end{array}$ \\
\hline $0-10$ & + & + & + & + & + & + \\
\hline $10-20$ & + & + & + & + & + & - \\
\hline $20-30$ & + & + & + & + & - & - \\
\hline $30-50$ & + & + & + & - & - & - \\
\hline $50-100$ & + & + & - & - & - & - \\
\hline $100-500$ & + & + & - & - & - & - \\
\hline $500-1000$ & + & - & - & - & - & - \\
\hline Over 1000 & - & - & - & - & - & - \\
\hline
\end{tabular}

Table 2.

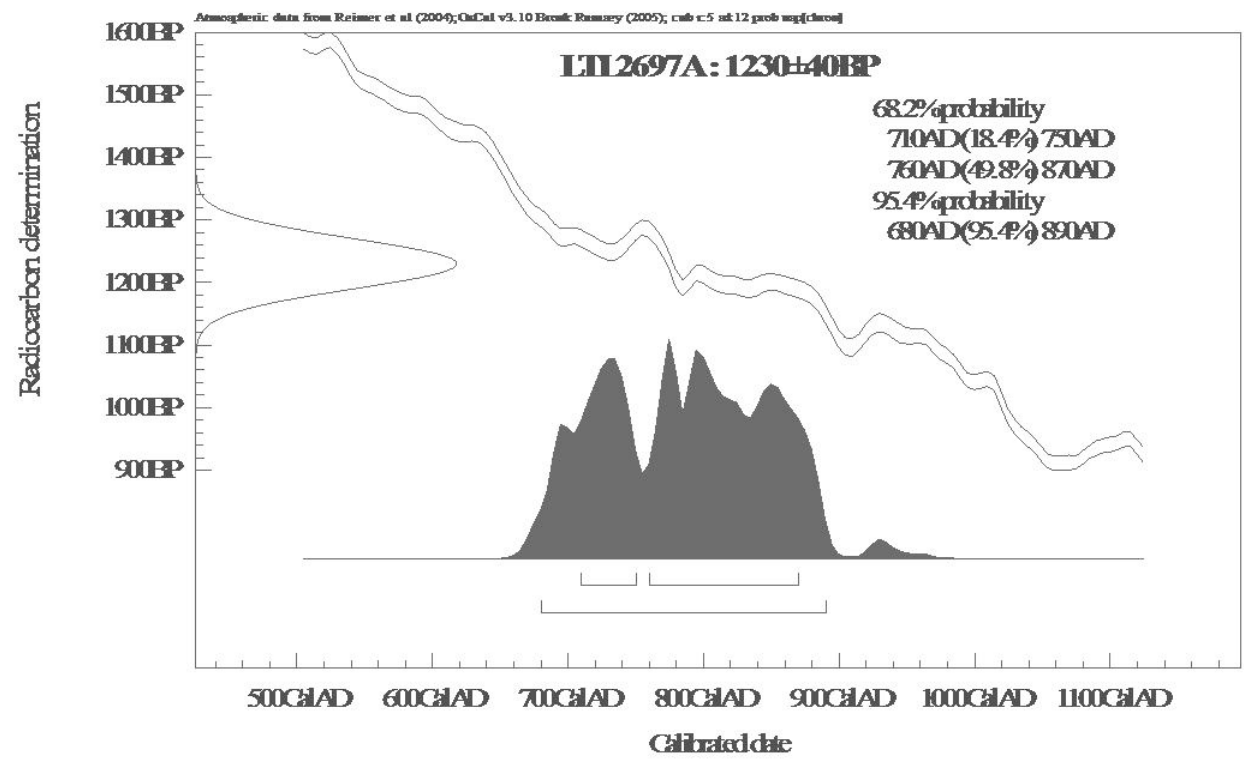

tions for the reservoir, and for this reason no further information can be gained on their cultural background.

\section{CONCLUSION}

The authors recognise the limitations of this work and acknowledge the benefit of involving a forensic anthropologist. However, the above case demonstrates the relevance of an odontological evaluation when discovered human remains include jaws and teeth. It allows for the collection of potentially valuable evidence and enhances observations and analysis. A consultant in forensic odontology and radiology is particularly helpful in establishing the detailed anatomy of a specimen, individual characteristics and age assessment, both in criminal and anthropological cases. This case confirms the importance of involving odontologists with a forensic background in non clinical applications such as physical anthropology during investigations on teeth, jaw and skull fossils. This is particularly relevant in those Countries where post mortem investigations are likely to be performed solely by forensic pathologists.

\section{DISCLOSURE}

The authors declare they have received no direct or indirect financial incentives or benefits from Planmeca, Aribex inc. and Trophy. All the expenses for this paper were supported by the authors themselves.

\section{REFERENCES}

[1] Mays S. Brickley M, Dodwell N. Human Bones from Archaeological Sites. Guidelines for Producing Assessment Documents and Analytical Reports. English Heritage, Swindon, 2002.

[2] Buikstra JE, Ubelaker D, Eds. Standards for Data Collection from Human Skeletal Remains: Proceedings of a Seminar at the Field 
Museum of Natural History. Arkansas Archaeological Survey Press, Fayetteville, 1994.

[3] Haglund WD, Sorg MH, Eds. Forensic Taphonomy: the postmortem faith of human remains. CRC press, Boca-Raton FL, 1997.

[4] Blaauw M, Christen JA. The problems of radiocarbon dating. Science 2005; 308(5728): 1551-3.

[5] Grün R. Direct dating of human fossils. Am J Phys Anthropol 2006; (Suppl 43): 2-48;

[6] Ubelaker DH, Buchholz BA, Stewart JE. Analysis of artificial radiocarbon in different skeletal and dental tissue types to evaluate date of death. J Forensic Sci 2006; 51(3): 484-8.

[7] Swift B, Lauder I, Black S, Norris J. An estimation of the postmortem interval in human skeletal remains: a radionuclide and trace element approach. Forensic Sci Int 2001; 117(1-2): 73-87.
[8] Mincer HH, Chaudhry J, Blankenship JA, Turner EW. Postmortem Dental Radiography. J Forensic Sci 2008; 53(2).

[9] Cameriere R, Brogi G, Ferrante L, Mirtella D, Vultaggio C, Cingolani M, Fornaciari G. Reliability in Age Determination by Pulp/ToothRatio in Upper Canines in Skeletal Remains. J Forensic Sci 2006; 51(4).

[10] Cameriere R, Ferrante L, Belcastro MG, Bonfigli B, Rastelli E, Cingolani M. Age estimation by Pulp/Tooth Ratio in Canines by Mesial and Vestibular Peri-Apical X-Rays. J Forensic Sci 2007; 52(5): 1151-5.

[11] Cameriere R, Gunha E, Sassaroli E, Nuzzolese E, Ferrante L. Age estimation by pulp/tooth area ratio in canines: study of a Portuguese sample to test. Forensic Sci Int 2009; 193(1-3): 128.e1-6.

(C) Nuzzolese et al.; Licensee Bentham Open.

This is an open access article licensed under the terms of the Creative Commons Attribution Non-Commercial License (http://creativecommons.org/licenses/by-nc/3.0/) which permits unrestricted, non-commercial use, distribution and reproduction in any medium, provided the work is properly cited. 